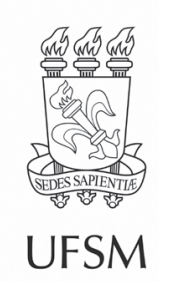

\title{
Artigos
}

\section{Anatomia comparada de Clethra scabra Pers. (Clethraceae) em diferentes altitudes na Serra da Mantiqueira, Minas Gerais, Brasil}

\author{
Comparative anatomy of Clethra scabra Pers. (Clethraceae) in different \\ altitudes in Serra da Mantiqueira, Minas Gerais state, Brazil
}

\begin{abstract}
Maria Luiza Santos ${ }^{\oplus}$, Alessandra de Oliveira Ribeiro" $\odot$, Evaristo Mauro de Castro"' ${ }^{\oplus}$, Kaline Fernandes Miranda"' $\odot$,

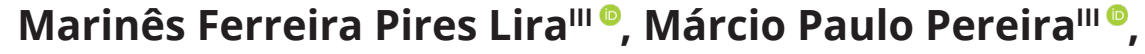
Cassiana Alves Ferreiralv $\oplus$, Fabio Akira Mori"I $\odot$
\end{abstract}

'Pesquisadora Autônoma, Aracaju, SE, Brasil

"Pesquisadora Autônoma, Lavras, MG, Brasil

"'Universidade Federal de Lavras, Lavras, MG, Brasil

IvUniversidad Continental, Huancayo, Província Junín, Peru

\section{RESUMO}

Para verificar a influência da altitude na estrutura anatômica de folhas e do xilema secundário de galhos de indivíduos da espécie Clethra scabra Pers. (Clethraceae) ocorrentes na Serra da Mantiqueira, estado de Minas Gerais, realizaram-se coletas de amostras nas cotas altitudinais de 1500, 1700, 1900 e $2100 \mathrm{~m}$ (metros). As folhas e galhos coletados foram fixados e preparados seguindo procedimentos usuais de microtécnica vegetal. Procederam-se análises anatômicas quantitativas utilizando software de análise de imagem. As folhas de C. scabra são hipoestomáticas com epiderme trisseriada e tricomas estrelados, mesofilo dorsiventral, parênquima paliçádico com uma a duas camadas celulares e o parênquima esponjoso com quatro. A nervura central com xilema desenvolvido e o feixe vascular envolvido pela bainha esclerenquimática. Análises de variância (ANOVA) e teste de Scott-Knott demonstraram que as espessuras do limbo foliar, mesofilo e parênquima paliçádico não apresentaram diferenças estatísticas significativas entre as altitudes avaliadas. O xilema secundário apresentou diminuição no comprimento dos elementos de vaso com o aumento da altitude na cota de $2100 \mathrm{~m}$ e o diâmetro tangencial dos elementos de vaso aumentaram nas duas menores altitudes e depois reduziram. Índices de vulnerabilidade de Carlquist e de mesomorfia diminuíram ao longo do gradiente altitudinal. Comprimento e diâmetro das fibras diminuíram com elevação da altitude. Assim, a altitude influencia nas modificações anatômicas apresentadas por folhas e galhos de C. scabra, que podem ser relacionadas a sua plasticidade fenotípica em resposta às diferentes condições ambientais.

Palavras-chave: Carne-de-vaca; Floresta nebular; Mesofilo; Xilema secundário 


\section{ABSTRACT}

To verify the influence of altitude on the anatomical structure of leaves and the secondary xylem of branches of individuals of the species Clethra scabra Pers. (Clethraceae) occurring in the Serra da Mantiqueira, state of Minas Gerais, samples were collected at altitudes of 1500, 1700, 1900 and $2100 \mathrm{~m}$ (meters). The collected leaves and branches were fixed and prepared following usual plant microtechnical procedures. Quantitative anatomical analyzes were performed using image analysis software. The leaves of C. scabra are hypoestomatic with triseriate epidermis and stellate trichomes, dorsiventral mesophyll, palisade parenchyma with one to two cell layers and the spongeous parenchyma with four. The central rib with developed xylem and the vascular bundle involved by the sclerenchyma sheath. Analysis of variance (ANOVA) and Scott-Knott test demonstrated that the thickness of the leaf blade, mesophyll and palisade parenchyma did not present statistically significant differences between the evaluated altitudes. The secondary xylem showed a decrease in the length of the vessel elements with increasing altitude at the $2100 \mathrm{~m}$ elevation and the tangential diameter of the vessel elements increased at the two lowest altitudes and then reduced. The Carlquist and the mesomorphic vulnerability indices decreased along the altitudinal gradient. Fiber length and diameter decreased with increasing altitude. Thus, altitude influences the anatomical changes presented by leaves and branches of $C$. scabra, which can be related to its phenotypic plasticity in response to different environmental conditions.

Keywords: Carne-de-vaca; Nebular forest; Mesophyll; Secondary xylem

\section{INTRODUÇÃO}

As florestas tropicais, como a Floresta Atlântica localizada na região tropical montanhosa sul-americana, concentram um elevado número de espécies endêmicas. No Brasil, a Floresta Atlântica é considerada um dos hotspots mundiais de biodiversidade (KIER et al., 2009) e compõe um dos principais tipos de vegetação natural, que ocupava mais de 1,3 milhões de $\mathrm{km}^{2}$, estendendo-se de forma contínua desde os estados do Rio Grande do Norte até o Rio Grande do Sul (IBGE, 2012). Contudo, devido ao desmatamento ocorrido no país em consequência da ocupação territorial, o que restou da vegetação natural e os remanescentes florestais foram em torno de 15,2\% (FUNDAÇÃO SOS MATA ATLÂNTICA; INSTITUTO NACIONAL DE PESQUISAS ESPACIAIS, 2018).

Na Serra da Mantiqueira, estado de Minas Gerais, ocorre um dos remanescentes da Floresta Atlântica no Brasil, sendo os conhecimentos sobre suas espécies vegetais ainda incipientes, visto que os estudos realizados estão focados, principalmente, na 
composição florística, estrutura e dinâmica de comunidades (MEIRELES; KINOSHITA; SHEPHERD, 2014; POMPEU et al., 2014) e anatômico (CRUZ et al., 2014; FREITAS, 2017; SOUZA, 2014). Nesse contexto, persiste a necessidade de ampliação nos estudos de estrutura foliar e do xilema secundário relacionados às variações ambientais provenientes do gradiente altitudinal presente nesta região. Em altitudes mais elevadas ocorrem diminuição de pressão atmosférica total e da pressão parcial dos gases oxigênio $\left(\mathrm{O}_{2}\right)$ e gás carbônico $\left(\mathrm{CO}_{2}\right)$, redução da temperatura do ar, aumento da radiação solar e elevação da radiação UV-B. Sendo assim, nesses ambientes, as plantas têm de se adaptarem para viver nessas condições (KÖRNER, 2007).

Em relação aos estudos para expressar a correlação ecologia-anatomia do xilema secundário de espécies, Carlquist (2001) sugere duas abordagens diferentes no que diz respeito aos métodos utilizados. Uma é fundamentada em grupos taxonômicos e visa à análise comparativa de espécies de um mesmo gênero em um gradiente ecológico. A outra envolve a comparação de pequenas áreas ou flórulas visando ao reconhecimento de caracteres anatômicos comuns a uma dada formação vegetal, independentemente de grupos taxonômicos.

Estudos anatômicos realizados na Serra da Mantiqueira das espécies Myrsine coriacea (Sw.) R.Br. ex Roem. \& Schult e Myrsine umbellata Mart. por Souza (2014), em diferentes altitudes em uma Floresta Ombrófila Densa Alto Montana, relataram modificações foliares nos valores de densidades estomáticas em respostas às maiores altitudes. Analisando a espécie Drimys brasiliensis Miers. Cruz et al. (2014) observaram que essa exibiu a formação de papilas na face abaxial das folhas e, ainda, apresentou modificações foliares na maior altitude examinada. Na espécie Prunus myrtifolia (L.) Urb., estudada por Freitas (2017), registrou-se aumento dos valores das variáveis fisiológicas também na maior altitude analisada.

A espécie estudada neste trabalho pertence à família Clethraceae, Eudicotyledoneae, Asteridae, ordem Ericales (ANGIOSPERM PHYLOGENY GROUP, 2016) representada pelos gêneros Clethra L. e Purdiaea Planch., composta por 
95 espécies e no Brasil existe apenas duas espécies de Clethra (PERDIZ; GIULIETTI; OLIVEIRA, 2015), sendo elas Clethra uleana Sleumer e Clethra scabra Pers. A espécie Clethra scabra Pers. é conhecida popularmente como carne-de-vaca, vassourão, folhade-bolo, guaperê e cajuja. Apresenta-se nos portes arbustivo e arbóreo; considerada espécie decídua, por perder as folhas durante a estação seca e as renovam na estação chuvosa, especialmente nos meses de maior precipitação de novembro a dezembro (PEREIRA et al., 2017). E, ainda, possui importância medicinal com o uso de infusão de suas folhas utilizadas no tratamento popular contra a malária (WANDERLEY, 2012).

Clethrascabra Pers.éuma espécie considerada restrita àsformações altimontanas das regiões Sul e Sudeste do país (MEIRELES; KINOSHITA; SHEPHERD, 2014). Essas formações são ainda pouco estudadas com ralação às características de anatomia ecológica. Assim, foi levantada a pergunta preliminar: as características anatômicas de folhas e do xilema secundário de galhos de C. scabra diferem entre as cotas altitudinais analisadas? Com isso, o presente estudo teve como objetivo caracterizar as estruturas anatômicas das folhas e do xilema secundário de galhos de C. scabra, ao longo do gradiente de altitude. De maneira a fornecer informações sobre a anatomia ecológica de uma espécie da Mata Atlântica mineira, além de contribuir com outros estudos das espécies vegetais de Floresta Ombrófila Alto Montana, presentes no município de Itamonte, Minas Gerais.

\section{MATERIAL E MÉTODOS}

\section{1 Área de estudo}

O estudo foi realizado na Serra da Mantiqueira, município de Itamonte, região Sul do estado de Minas Gerais, Brasil, nas coordenadas geográficas cerca de $22^{\circ} 21^{\prime} 55^{\prime \prime} \mathrm{S}$

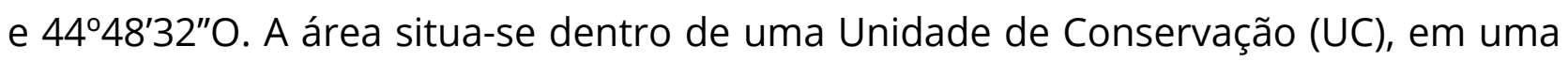
Reserva Particular do Patrimônio Natural (RPPN) Alto Montana, localizada na Fazenda Pinhão Assado, contendo 672 hectares. O clima da região é do tipo Cwb da classificação 
de Köppen, temperado úmido com inverno seco e verão temperado, segundo Sá Júnior et al. (2012) (Figura 1). A vegetação está constituída pelas Florestas Semideciduais Submontana, Montana e a Alto Montana e, nessa, encontram-se refúgios da "mata nuvígena ou mata nebular" (IBGE, 2012) ou floresta nebular, apontada entre as mais ameaçadas de todas as vegetações florestais dos trópicos. A precipitação média anual é de aproximadamente 1.449 mm e a temperatura média nas altitudes de 1500, 1700, 1900 e 2100 metrossão de respectivamente: $16,0^{\circ} \mathrm{C} ; 14,5^{\circ} \mathrm{C} ; 13,5^{\circ} \mathrm{C}$ e $11,80^{\circ} \mathrm{C}$, já a média da umidade relativa do ar nas cotas descritas acima sequencialmente são de: 78\%, 79,47\% 81\% e $87,68 \%$ (Watchdog 2900ET). Os dados foram obtidos por meio de monitoramento realizado no ano de 2018 por estações meteorológicas (Watchdog modelo2900ET) instaladas em cada cota altitudinal.

Figura 1 - Área de estudo na Reserva Particular do Patrimônio Natural (RPPN) Alto Montana, no município de Itamonte - Minas Gerais, Brasil

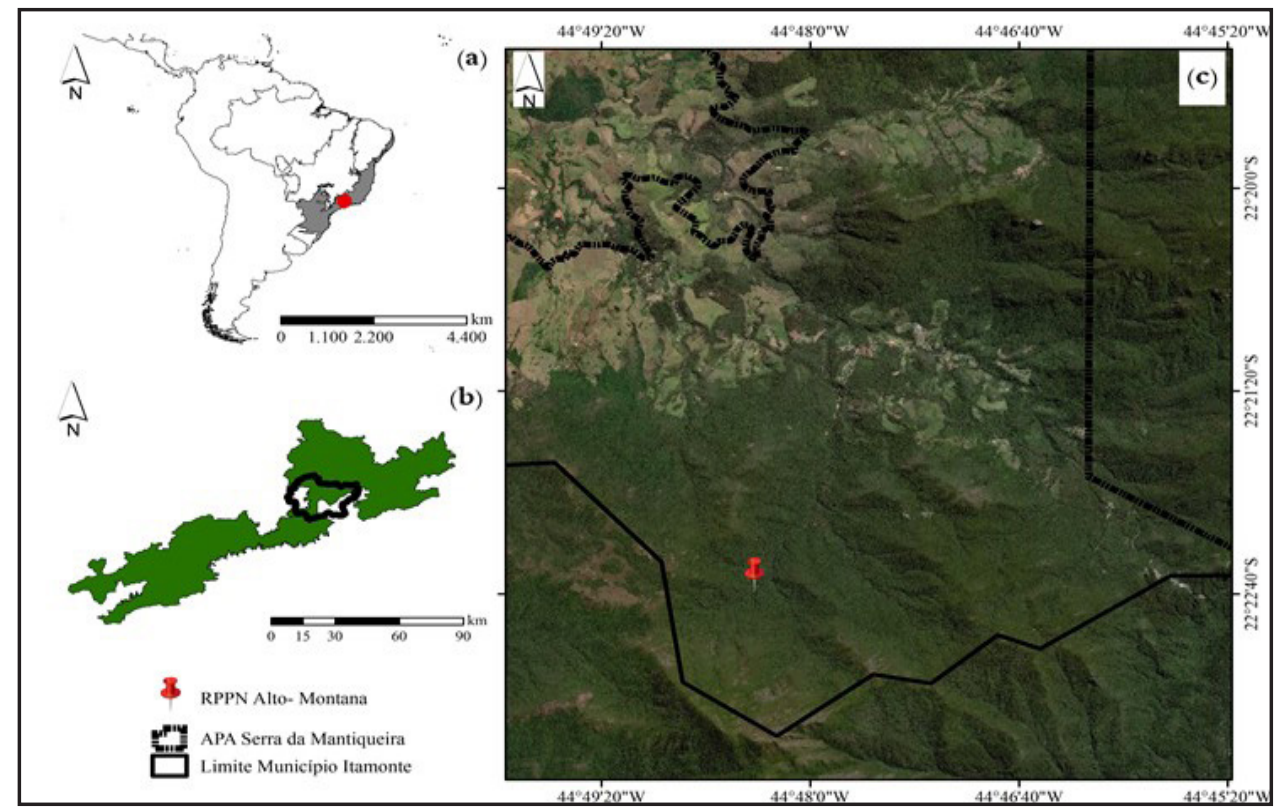

Fonte: IBGE (2015); Instituto Chico Mendes de Conservação da Biodiversidade (2018)

Em que: a - Brasil na América do Sul e localização da área de estudo no estado de Minas Gerais, na região Sudeste do país; b - Localização do Município de Itamonte na APA da Mantiqueira; c- Localização da Reserva Particular do Patrimônio Natural (RPPN) Alto Montana e área de coletas no ponto destacado em vermelho. 


\subsection{Coleta e preparo das amostras}

As coletas das folhas e galhos de Clethra scabra ocorreram em junho de 2018 nas cotas altitudinais de 1500, 1700, 1900 e 2100 m. Em cada cota de altitude foram selecionados cinco indivíduos (repetições) que estavam presentes em duas parcelas de $20 \mathrm{~m} \times 20 \mathrm{~m}$. De cada indivíduo foram coletados 2 (dois) galhos localizados na segunda bifurcação em relação ao comprimento total da árvore. De cada galho foram retiradas amostras a 0,50 , e $100 \%$ do seu comprimento total. Os galhos retirados tinham em média de 2,0 a 3,0 cm. Para cada indivíduo, calculou-se o valor médio em relação a cada variável.

Folhas completamente expandidas, livres de patógenos e herbivoria, foram coletadas da face leste da copa, totalizando 20 por indivíduo. Nesse caso, realizaram-se as medições dos tecidos em cada folha, obtendo-se o valor médio por indivíduo, para cada cota. Após a coleta, as amostras foram fixadas em F.A.A.70\% (formaldeído, ácido acético e etanol 70\% por 72 horas e transferidas para etanol a 70\%) até a realização das análises microscópicas (KRAUS; ARDUIM, 1997). O material botânico voucher sob o número ESAL-30.528 encontra-se depositado no Herbário da Universidade Federal de Lavras, município de Lavras, Minas Gerais.

\subsection{Anatomia foliar}

Fragmentos da região mediana das folhas foram desidratados em concentrações crescentes de etanol (70, 80, 90 e 100\%) em intervalos de $2 \mathrm{~h}$ (horas) cada. Seguiu-se com a imersão dessas em solução de pré-infiltração, composta por etanol 100\% e resina base (1:1) por $24 \mathrm{~h}$. Para a polimerização, as amostras foram incorporadas em historesina (Leica Historresin $®$ ), segundo as instruções do fabricante e colocadas para secar em estufa a $50^{\circ} \mathrm{C}$. Secções transversais foram obtidas em micrótomo rotativo semiautomático Yidi YD-335 (JinhuaYidi Medical Appliance CO., LTD, Zhejiang, China).

As lâminas foram coradas em solução de Azul de toluidina 1\% (O `BRIEN; FEDER e MCCULLY, 1965) e montadas com Entellan ${ }^{\circledR}$. E, em seguida, foram fotografadas 
em microscópio Zeiss Microimaging GmbH Scope A1 com câmera digital acoplada (AxionCam ERc5s) e as imagens analisadas por meio do software UTHSCSA-Image Tool 3.0 para avaliações quantitativas.

Foram analisadas 8 (oito) folhas/indivíduo, totalizando 40 folhas por cota altitudinal. As variáveis analisadas foram: espessura da cutícula da face adaxial, epidermes das faces adaxial e abaxial, espessura dos parênquimas paliçádico e esponjoso, espessuras do mesofilo e do limbo foliar.

\subsection{Anatomia dos galhos}

Para as análises anatômicas dos galhos, foram analisados 3 (três) galhos/ indivíduo, sendo que de cada galho retirou-se uma amostra a 0,50 e 100\% do comprimento total de cada galho, totalizando 45 galhos por cota altitudinal. Os corpos de provas (galhos retirados diretamente da solução fixante) foram seccionados em micrótomo de deslize - modelo Leica SM 2000R, com espessura de $16 \mu$ m nas seções transversais e longitudinal (tangencial). Secções obtidas foram clarificadas em solução de hipoclorito de sódio comercial, lavadas em álcool 20\% e coradas com safranina aquosa 1\% e azul de alcian aquoso 1\%, na proporção de 1:9 (KRAUS; ARDUIM, 1997). Após a coloração, secções foram desidratadas em concentrações crescentes de etanol (30, 50, 70, 90 e 100\%) e fixadas em álcool/acetato de butila (nas proporções: 3:1; 1:1, 1:3) e, subsequentemente, em acetato de butila 100\%. As lâminas foram montadas com resina sintética Entellan ${ }^{\circledR}$.

A dissociação dos elementos celulares foi realizada seguindo a metodologia de Franklin (1945), feita com solução macerante de peróxido de hidrogênio e ácido acético, nas proporções de 1:1, em uma estufa a $60^{\circ} \mathrm{C}$ por $24 \mathrm{~h}$. Posteriormente, realizou-se a lavagem em água corrente, até a retirada da solução macerante. $\mathrm{O}$ material foi corado com safranina $1 \%$ e montado em lâminas com glicerina. Lâminas foram fotografadas em microscópio Olympus modelo $\mathrm{BH}-2$ acoplado a uma câmera digital por meio do software analisador Wincell, obtendo-se de forma direta a 
mensuração dos elementos celulares. Para cada característica anatômica observada, foram realizadas 30 medições/indivíduo.

As variáveis mensuradas foram: comprimento, diâmetro tangencial e frequência dos elementos de vaso; diâmetro das pontoações intervasculares, frequência dos raios, comprimento, diâmetro do lume e espessura das paredes das fibras. O índice de vulnerabilidade foi calculado pela fórmula diâmetro de vaso/frequência de vaso e o índice de mesomorfia pela fórmula índice de vulnerabilidade $x$ comprimento de elementos de vaso, conforme proposto por Carlquist (2001). As análises microscópicas qualitativas e quantitativas foram descritas conforme IAWA Committee (1989).

\subsection{Análises estatísticas}

A normalidade da distribuição de dados foi verificada por meio do teste de Shapiro-Wilk. ANOVA foi utilizada para testar a significância das diferenças nas características anatômicas das folhas e do xilema secundário dos galhos observados na espécie estudada, com o auxílio do pacote Sisvar® versão 5.0 (FERREIRA, 2011). As diferenças entre as médias foram avaliadas pelo teste de Scott-Knott e os valores de $p$ $\leq 0,05$ foram considerados estatisticamente significativos.

\section{RESULTADOS E DISCUSSÃO}

\subsection{Anatomia foliar}

Como se pode observar na Figura $2 \mathrm{a}$, as folhas de Clethra scabra são hipoestomáticas, possuindo estômatos localizados em depressões da epiderme. Ocorre alta densidade de tricomas tectores estrelados, localizados nas depressões na face abaxial epidérmica. A epiderme da face adaxial é trisseriada, composta de duas a três camadas e a da face abaxial possui apenas uma, revestida em toda a sua extensão por cutícula. O mesofilo é dorsiventral, com parênquima paliçádico composto de uma a duas camadas e o esponjoso com quatro a cinco camadas celulares. O sistema vascular 
é do tipo colateral envolvido por uma bainha esclerenquimática que se estende para a epiderme de ambas as faces.

Figura 2 - Secções transversais de folhas de Clethra scabra em diferentes cotas altitudinais em Itamonte - Minas Gerais, Brasil

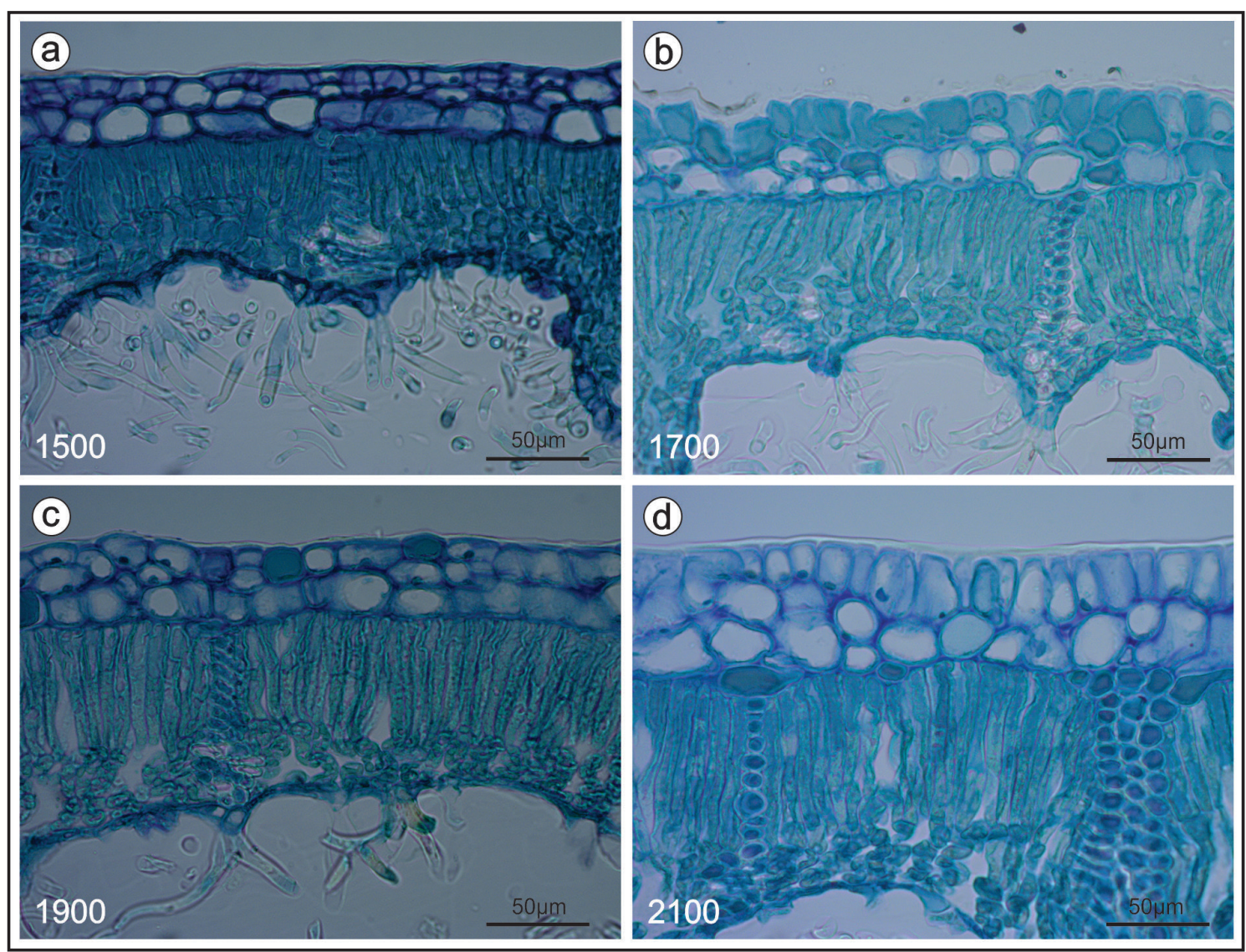

Fonte: Autores (2019)

Em que: cut - cutícula; ep- epiderme adaxial; pp - parênquima paliçádico; pe -parênquima esponjoso; tr - tricomas tectores estrelados; ebf- envoltório da bainha do feixe.

Entre as cotas de altitudes, verifica-se que as folhas em relação às espessuras do limbo, do mesofilo, dos parênquimas paliçádico e esponjoso exibiram aumento ao longo do gradiente altitudinal apresentadas na Tabela 1 e na Figura 2. As espessuras do limbo aumentaram significativamente com a altitude, o mesofilo seguiu o mesmo padrão com aumento da altitude, assim como os parênquimas paliçádico e esponjoso, respectivamente (Tabela 1). 
Tabela 1 - Características quantitativas da anatomia foliar de Clethra scabra ocorrente em diferentes cotas de altitude em um fragmento de Floresta Ombrófila Alto Montana, município de Itamonte - Minas Gerais, Brasil

\begin{tabular}{lcccc}
\hline \multicolumn{1}{c}{ Características } & \multicolumn{4}{c}{ Cotas altitudinais $(\mathbf{m})$} \\
\cline { 2 - 5 } \multicolumn{1}{c}{ anatômicas $(\boldsymbol{\mu m})$} & $\mathbf{1 5 0 0}$ & $\mathbf{1 7 0 0}$ & $\mathbf{1 9 0 0}$ & $\mathbf{2 1 0 0}$ \\
\hline Cutícula adaxial & $1,89 \mathrm{c} \pm 0,48$ & $2,90 \mathrm{a} \pm 0,60$ & $3,01 \mathrm{a} \pm 0,67$ & $2,39 \mathrm{~b} \pm 0,69$ \\
Epiderme adaxial & $28,66 \mathrm{c} \pm 4,92$ & $33,83 \mathrm{~b} \pm 6,38$ & $35,01 \mathrm{~b} \pm 7,37$ & $42,03 \mathrm{a} \pm 9,85$ \\
$\begin{array}{l}\text { Parênquima } \\
\text { paliçádico }\end{array}$ & $41,84 \mathrm{~d} \pm 7,97$ & $48,37 \mathrm{c} \pm 6,29$ & $55,09 \mathrm{~b} \pm 8,32$ & $58,99 \mathrm{a} \pm 11,15$ \\
Parênquima & & & & \\
esponjoso & $22,32 \mathrm{c} \pm 5,63$ & $28,51 \mathrm{~b} \pm 8,39$ & $31,41 \mathrm{a} \pm 8,28$ & $33,85 \mathrm{a} \pm 8,48$ \\
Epiderme abaxial & $6,02 \mathrm{a} \pm 1,42$ & $5,64 \mathrm{a} \pm 1,10$ & $5,03 \mathrm{~b} \pm 1,08$ & $5,10 \mathrm{~b} \pm 1,08$ \\
Limbo & $100,73 \mathrm{~d} \pm 14,16$ & $119,25 \mathrm{c} \pm 12,46$ & $129,56 \mathrm{~b} \pm 16,50$ & $142,36 \mathrm{a} \pm 22,44$ \\
Mesofilo & $64,17 \mathrm{c} \pm 11,15$ & $83,61 \mathrm{~b} \pm 12,93$ & $86,50 \mathrm{~b} \pm 11,65$ & $92,84 \mathrm{a} \pm 17,03$ \\
\hline
\end{tabular}

Fonte: Autores (2019)

Em que: * As médias seguidas da mesma letra nas linhas não diferem entre si pelo teste ScottKnott $(p<0,05)$.

A ocorrência de folhas mais espessas (Tabela 1 e Figura 2) em altas altitudes foi observada por Kuster; Castro; Vale (2016). No entanto, Freitas (2017) e Souza (2014) registraram folhas menos espessas em altas altitudes. Provavelmente, isso está associado à ocorrência de neblina, maior influência das nuvens e na umidade relativa do ar a uma menor temperatura. Boanares et al. (2018) declararam que as folhas têm a capacidade de absorver a água em forma de neblina e, assim, podem contribuir positivamente para o balanço hídrico e de carbono em ecossistemas montanhosos. Nesse mesmo estudo, esses autores observaram que a difusão de água através da cutícula e de tricomas ocorreram nas espécies estudadas: Leandra australis (Cham.) Cogn. e Miconia corallina Spring. (Melastomataceae), Eremanthus erythropappus (DC.) MacLeish, (Asteraceae), Byrsonima variabilis A.Juss., (Malpighiaceae), Senna reniformis (G.Don) H.S.Irwin \& Barneby (Fabaceae), Ouratea semiserrata (Mart.) Engl. (Ochnaceae) e Myrcia splendens (Sw.) DC (Myrtaceae). Dessa forma, os registros deste estudo podem ter relação com a absorção de água na formação de neblina, uma vez que 
uma cutícula e epiderme (Tabela 1) mais finas podem facilitar sua absorção. Cruz et al. (2014) encontraram resultado semelhante para a espessura da cutícula na espécie Drimys brasiliensis Miers. Os autores relatam que o nevoeiro pode servir como uma barreira contra a penetração direta de raios solares, o que reduziria a necessidade de proteção realizada por uma cutícula mais espessa.

Em relação às características anatômicas foliares, Souza (2014) demonstrou que a espessura dos tecidos foliares de Myrsine coriacea (Sw.) R.Br. ex Roem. \& Schult e Myrsine umbellata Mart. aumentou na maior altitude $(2100 \mathrm{~m})$ e mencionou a presença de inúmeros espaços intercelulares no mesofilo. Na mesma altitude, Freitas (2017) registrou que na espécie Prunus myrtifolia (L.) Urb o mesofilo foi mais espesso com suas células agrupadas formando menor porosidade. Em contraste, Cruz et al. (2014), estudando Drimys brasiliensis Miers., relataram que na altitude supracitada a espécie exibiu uma diminuição na espessura dos tecidos foliares e um aumento de espaços intercelulares do mesofilo. Os autores explicaram que esses espaços podem aumentar a área disponível para a absorção do $\mathrm{CO}_{2}$ na maior altitude, na qual ocorre redução da pressão desse gás. Esses autores ainda argumentaram que cada planta tem características e mecanismos adaptativos únicos e peculiares a cada espécie. Assim, as alterações adaptativas dependem da estrutura da folha, da forma de vida da planta, dos caracteres ecológicos, além da altitude, do habitat em que essas estão inseridas.

\subsection{Anatomia dos galhos}

O xilema secundário dos galhos (Figura 3a) apresenta anéis de crescimento distintos, delimitados por uma camada de fibras com parede mais espessa, formando zonas fibrosas. A porosidade dos vasos é difusa, representada por $90,33 \%$ de vasos solitários com contorno angular e 9,67\% de vasos múltiplos (geminados em sua maioria). A média do diâmetro tangencial dos elementos de vaso é de 35,98 $\mu \mathrm{m}$, tendo a frequência de $309,70 / \mathrm{mm}^{2}$ e comprimento de $517,92 \mu \mathrm{m}$. Os raios são de dois tamanhos distintos: unisseriados e multisseriados ( 2 a 5 células) (Figura 3b) e há presença de células envolventes e raios fusionados (Figura 3c, seta branca). 
Figura 3 - Características anatômicas dos galhos de Clethra scabra em diferentes cotas altitudinais em Itamonte - Minas Gerais, Brasil

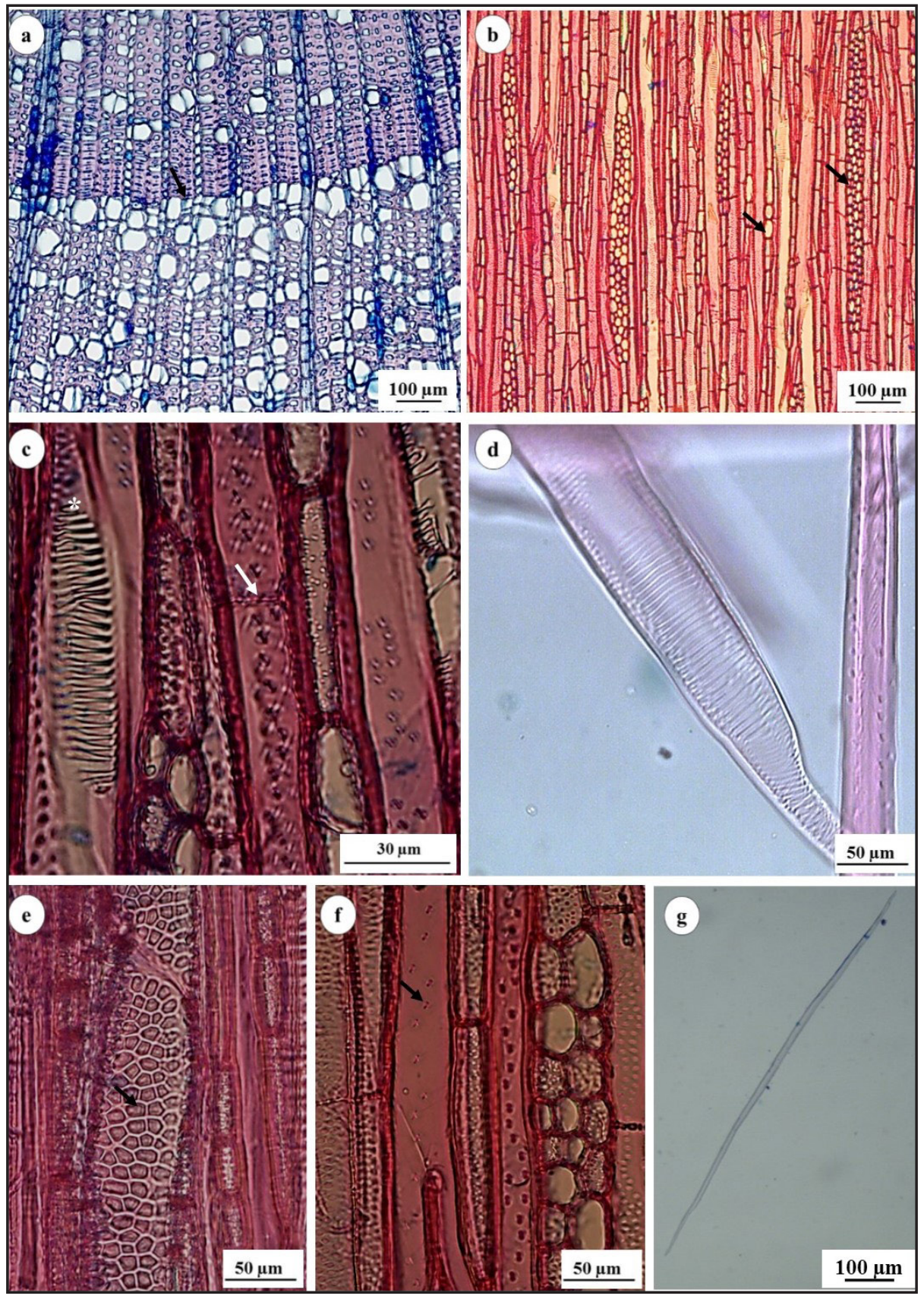

Fonte: Autores (2019)

Em que: a- anéis de crescimento distinto por camadas de fibras com parede mais espessa - seta, porosidade difusa (seção transversal); braios uni e multisseriados - seta (seção tangencial); c- placa de perfuração escalariforme - asterisco e fibra septada - seta branca (seção tangencial); d- placa de perfuração escalariforme (macerado); e- pontoações intervasculares alternas com formato poligonal - seta (seção tangencial); f- fibrotraqueídes com pontoações grandes e areoladas - seta (seção tangencial); g- fibra libriforme (macerado). 
Os elementos de vaso apresentam placa de perfuração escalariforme com 20 a 40 barras (Figuras 3c e 3d) e espessamento da parede do tipo helicoidal, e apêndices podem ou não ocorrer em uma ou em ambas as extremidades. As pontoações intervasculares são alternas com formato poligonal, pequenas e com média de 4,5 $\mu \mathrm{m}$ (Figura 3e). As fibras são libriformes curtas ou medianas, com o comprimento médio de

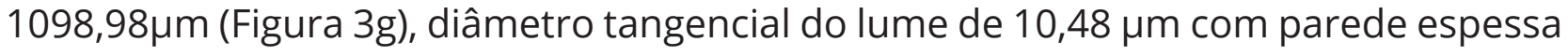
de 4,47 $\mu \mathrm{m}$, pontoações diminutas presentes e septadas (Figura 3d). Fibrotraqueídes presentes, com pontoações grandes e areoladas (Figura 3f). O parênquima axial paratraqueal apresenta dois tipos: vasicêntrico e escasso, com 3 a 7 células de bainha na secção tangencial.

As modificações significativas ocorridas na anatomia do xilema secundário dos galhos ao longo do gradiente altitudinal são mostradas na Tabela 2 e Figura 4. O comprimento dos elementos de vaso apresentou diminuição com o aumento altitudinal. Em relação ao diâmetro tangencial, os elementos de vaso apresentaram aumentos entre as duas menores cotas altitudinais (Figuras 4a-b) e reduções nas duas maiores (Figuras 4c-d). O índice de vulnerabilidade de Carlquist e de mesomorfia diminuíram ao longo do gradiente altitudinal, bem como o comprimento das fibras. A espessura das paredes das fibras aumentou significativamente conforme aumentou a altitude. A frequência de vasos $/ \mathrm{mm}^{2}$ não diferiu entre as cotas altitudinais analisadas, com média de 309,17 vasos/mm². As ocorrências dos vasos solitários reduziram com o aumento da altitude e houve aumentos dos vasos múltiplos (Figuras 4c-d).

Conforme os dados apresentados na Tabela 2, neste estudo, verificou-se a redução no comprimento e do diâmetro tangencial dos elementos de vaso nas duas maiores altitudes (Figuras 4c-d). De acordo com Choat et al. (2012), vasos mais curtos e mais estreitos proporcionam uma maior segurança na condução hídrica, sendo menos susceptíveis à formação de bolhas de ar. Em contrapartida, a presença de elementos de vaso mais compridos e mais largos, nos indivíduos localizados na menor altitude, implica uma maior eficiência no fluxo de água, porém se tornam mais vulneráveis. Essa 
ocorrência pode ser explicada devido às altas pressões negativas dentro dos vasos, aumentando o risco de embolismo, bloqueando assim o sistema de condução na planta (BARAJAS-MORALES, 1985). Florez et al. (2017) relatam que a condição de floresta nebular, abaixo de constantes ações da cobertura média de nuvens, interferiram na formação de elementos de vaso mais compridos e com diâmetro reduzido nos locais mais altos.

Tabela 2 - Características quantitativas da anatomia do xilema secundário de Clethra scabra ocorrente em diferentes cotas de altitude em um fragmento de Floresta Ombrófila Alto Montana, município de Itamonte - Minas Gerais, Brasil

\begin{tabular}{|c|c|c|c|c|}
\hline \multirow{2}{*}{$\begin{array}{c}\text { Características } \\
\text { anatômicas }\end{array}$} & \multicolumn{4}{|c|}{ Cotas altitudinais (m) } \\
\hline & 1500 & 1700 & 1900 & 2100 \\
\hline $\begin{array}{l}\text { Comprimento dos } \\
\text { elementos de vasos }(\mu \mathrm{m})\end{array}$ & $565,91 a \pm 31,19$ & $527,36 a \pm 41,29$ & $502,06 b \pm 37,70$ & $471,12 b \pm 29,40$ \\
\hline $\begin{array}{l}\text { Diâmetro tangencial dos } \\
\text { vasos }(\mu \mathrm{m})\end{array}$ & $38,10 a \pm 4,10$ & $40,76 a \pm 5,06$ & $35,01 b \pm 2,62$ & $30,81 b \pm 3,05$ \\
\hline $\begin{array}{l}\text { Frequência dos vasos } \\
\left(\mathrm{mm}^{2}\right)\end{array}$ & $271,83 a \pm 10,00$ & $300,40 a \pm 41,60$ & $349,46 a \pm 63,66$ & $317,09 a \pm 38,63$ \\
\hline $\begin{array}{l}\text { Índice de vulnerabilidade } \\
(\mu \mathrm{m})\end{array}$ & $0,14 a \pm 0,02$ & $0,14 a \pm 0,02$ & $0,10 b \pm 0,01$ & $0,10 b \pm 0,01$ \\
\hline $\begin{array}{l}\text { Índice de mesomorfia } \\
(\mu \mathrm{m})\end{array}$ & $79,75 a \pm 13,28$ & $72,92 a \pm 15,63$ & $50,92 b \pm 4,18$ & $46,14 b \pm 5,98$ \\
\hline $\begin{array}{l}\text { Comprimento das fibras } \\
(\mu \mathrm{m})\end{array}$ & $\begin{array}{c}1224,23 a \pm \\
159,71\end{array}$ & $\begin{array}{c}1177,49 a \pm \\
307,53\end{array}$ & $\begin{array}{c}1027,68 b \pm \\
185,66\end{array}$ & $\begin{array}{c}962,53 b \pm \\
191,50\end{array}$ \\
\hline $\begin{array}{l}\text { Espessura da parede das } \\
\text { fibras }(\mu \mathrm{m})\end{array}$ & $4,14 b \pm 0,84$ & $4,27 b \pm 0,87$ & $4,44 b \pm 1,06$ & $5,03 a \pm 1,09$ \\
\hline
\end{tabular}

Fonte: Autores (2019)

Em que: * As médias seguidas da mesma letra nas linhas não diferem entre si pelo teste Scott$\operatorname{Knott}(p<0,05)$.

Em relação aos índices de vulnerabilidade de Carlquist e de mesomorfia (Tabela 2) aqui analisados, também resultaram em valores significativamente menores nas duas altitudes maiores. Esses índices retratam a relação dos elementos de vaso com o ambiente, sendo que valores mais baixos proporcionam uma maior segurança no 
transporte de água e menor suscetibilidade à cavitação. O fato de os valores desses índices serem mais baixos em altitudes maiores é devido à presença de elementos de vaso curtos, com pequeno diâmetro e mais numerosos (CARLQUIST; HOEKMAN, 1985). Em maiores altitudes existe uma tendência a um maior agrupamento de vasos, devido à menor disponibilidade hídrica (CARLQUIST; HOEKMAN, 1985) que pode acontecer no período sem nevoeiros, levando ao aumento da radiação solar e tempo aproximado de radiação termal, e alta fração da radiação UV-B que interferiram na anatomia das plantas (KÖRNER, 2007).

Figura 4 - Secções transversais dos galhos de Clethra scabra em diferentes cotas altitudinais em Itamonte - Minas Gerais, Brasil

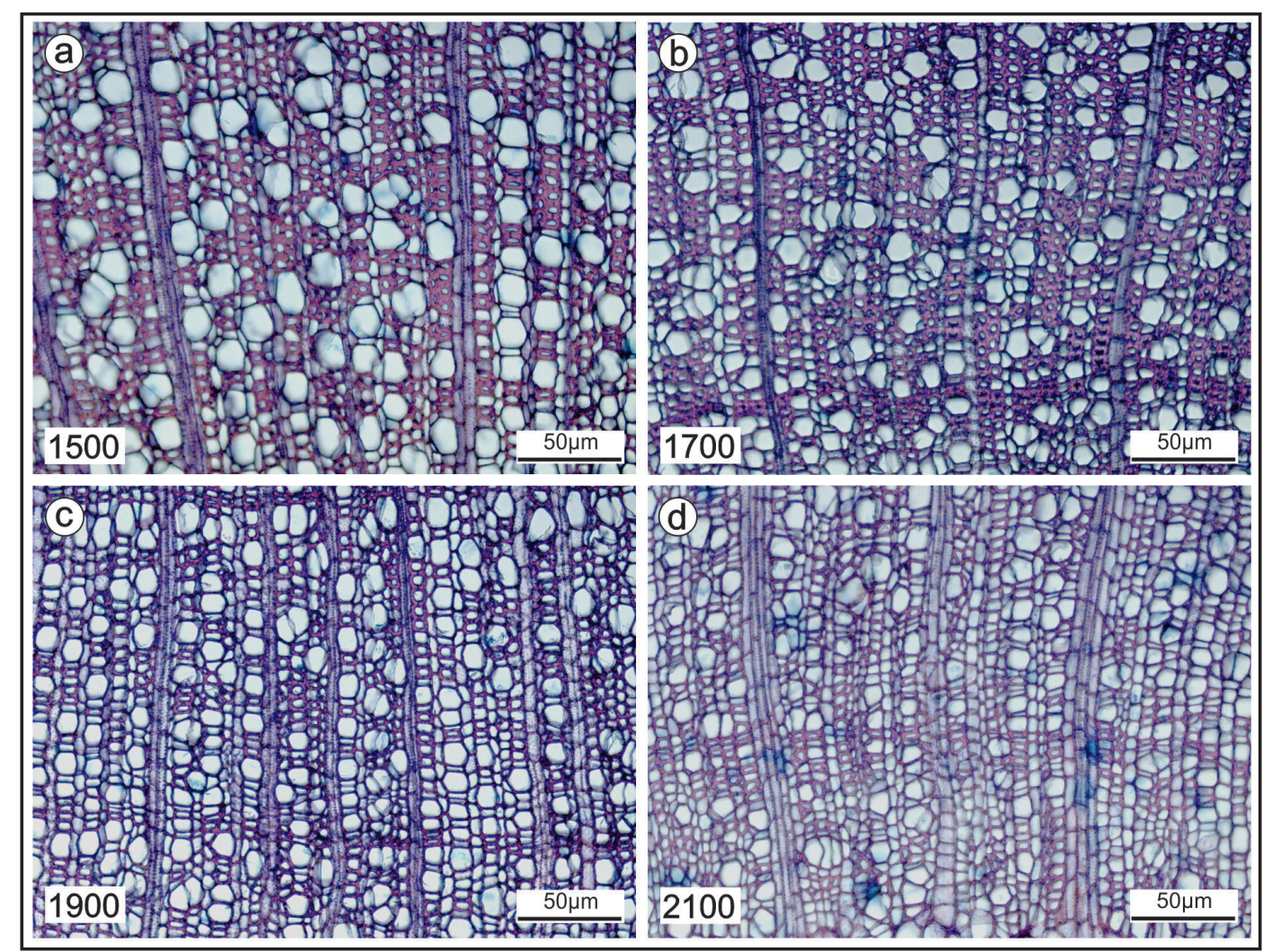

Fonte: Autores (2019)

Em que: Setas - diâmetro tangencial dos vasos.

Conforme os dados obtidos, foi observado que as fibras diminuíram os comprimentos da menor altitude para a maior altitude. Em contrapartida, a espessura 
da parede das fibras aumentou significativamente, inversamente proporcional à altitude, demonstrando que o aumento da altitude implica o comprimento das fibras concordando com o estudo realizado por Denardi e Marchiori (2005) com Blepharocalix salicifolius (HBK) Berg., que encontraram fibras mais curtas também em locais de menor altitude. Ainda em relação às fibras, verificou-se que a espessura das paredes mais finas é mais frequente em baixas altitudes, enquanto os maiores valores foram encontrados em altitudes maiores. Longui et al. (2012) propõem em estudos que em regiões montanhosas, espécies que apresentam fibras com paredes mais espessas suportam maiores esforços, tornando-as mais resistentes.

\section{CONCLUSÕES}

O presente estudo agrega valor sobre a anatomia ecológica da espécie Clethra scabra, presente nas florestas Ombrófilas Alto Montana da Mata Atlântica. As características anatômicas de folhas e do xilema secundário da espécie diferiram ao longo do gradiente altitudinal, sendo mais evidentes na maior altitude, indicando capacidade de ajuste das folhas diante das variações ambientais. De forma similar, a anatomia do xilema secundário dos galhos indica que as modificações nos elementos de vaso são mais marcantes na maior altitude, estando, provavelmente, relacionadas à segurança e à eficiência no transporte hídrico. Assim, a altitude influencia nas modificações anatômicas apresentadas por folhas e galhos de Clethra scabra, que podem ser relacionadas com sua plasticidade fenotípica em resposta às diferentes condições ambientais.

\section{REFERÊNCIAS}

ANGIOSPERM PHYLOGENY GROUP IV. An update of the Angiosperm Phylogeny Group classification for the orders and families of flowering plants: APG IV. Botanical Journal of the Linnean Society, London, v. 181, p. 1-20, apr. 2016.

BARAJAS-MORALES, J. Wood structural difference between trees of the tropical forests in Mexico. IAWA Bulletin, Beijing, v. 6, n. 4, p. 355-364, 1985. 
BOANARES, D. et al. Strategies of leaf water uptake based on anatomical traits. Plant Biology, [s. I.], v. 20, n. 5, p. 848-856, 2018.

CARLQUIST, S. Comparative wood anatomy: systematic, ecological and volutionary. New York: Springer, 2001. 418 p.

CARLQUIST, S.; HOEKMAN, D. A. Ecological wood anatomy of the woody southern Californian flora. IAWA Bulletin, Beijing, v. 6, n. 4, p. 319-347, 1985.

CHOAT B. et al. Global convergence in the vulnerability of forests to drought. Nature, London, v. 491, n. 752, p. 752-756, 2012.

CRUZ, B. P. da. et al. Comparison of leaf anatomy and essential oils from Drimys brasiliensis Miers. in a montane cloud forest in Itamonte, MG, Brazil. Botanical Studies, [s. I.], v. 55, n. 1, p. 41, 2014.

DENARDI, L.; MARCHIORI, J. N. C. Anatomia ecológica da madeira de Blepharocalyx salicifolius (HBK) Berg. Ciência Florestal, Santa Maria, v. 15, n. 2, p. 119-127, 2005.

FERREIRA, D. F. Sisvar: a computer statistical analysis system. Ciência e Agrotecnologia, Lavras, v. 35, n. 6, p. 1039-1042, nov./dez. 2011.

FLOREZ, J. B. et al. Anatomia do xilema secundário e da casca de llex theezans Mart.ex Reissek em Floresta Ombrófila Mista. In: CBCTEM CONGRESSO BRASILEIRO DE CIÊNCIA E TECNOLOGIA DA MADEIRA, 3. Anais [...]. [S. I: s. n.], 2017. v. 2. p. 1-12.

FRANKLIN, G. L. Preparation of thin sections of synthetic resin and wood: resin composites, and a new macerating method for wood. Nature, London, v. 155, n. 3924, p. 51, 1945.

FREITAS, B. S. M. de. Anatomia foliar e trocas gasosas de Prunus myrtifolia (L.) Urb em diferentes altitudes na Serra da Mantiqueira - MG. 2017. Dissertação (Mestrado em Botânica Aplicada) - Universidade Federal de Lavras, Lavras, MG, 2017.

FUNDAÇÃO SOS MATA ATLÂNTICA; INSTITUTO NACIONAL DE PESQUISAS ESPACIAIS (Brasil). Atlas dos remanescentes florestais da mata atlântica período 2016-2017. Relatório Técnico. São Paulo, 2018. 63 p.

IAWA COMMITTEE. International Association of Wood Anatomists. List of microscopic features for hardwood identification. IAWA Bulletin, Beijing, v. 10, n. 3, p. 220-332, 1989.

IBGE. Manual técnico em geociências. Manual técnico da vegetação brasileira. 2. ed. rev. e ampl. Rio de Janeiro, 2012. 271 p.

IBGE. Programa Arcamp 10.7.1, arquivos vetoriais, 2015. [S. I.], 2015. Disponível em: https:// mapas.ibge.gov.br/politico-administrativo/regionais. Acesso em: 05 maio 2018. 
INSTITUTO CHICO MENDESDE CONSERVAÇÃO DA BIODIVERSIDADE. Apa Serra da Mantiqueira. Brasília, 2018. Disponível em: http://www.icmbio.gov.br/portal/unidadesdeconservacao/ biomas-brasileiros/mata-atlantica/unidades-de-conservacao-mata-atlantica/2177-apa-daserra-da-mantiqueira. Acesso em: 02 out. 2018.

KIER, G. et al. A global assessment of endemism and species richness across island and mainland regions. PNAS, [s. I.], v. 106, n. 23, jun. 2009. DOI: 10.1073 pnas.081030610.

KÖRNER, C. The use of "altitude" in ecological research. Trends in Ecology and Evolution, [s. I.], v. 22, n. 11, p. 569-574, nov. 2007.

KRAUS, J. E.; ARDUIN, M. Manual básico de métodos em morfologia vegetal. Rio de Janeiro: EDUR, 1997. 198 p.

KUSTER, V. C.; CASTRO, S. A. B. de; VALE, F. H. A. Photosynthetic and anatomical responses of three plant species at two altitudinal levels in the Neotropical savannah. Australian Journal of Botany, Clayton, v. 64, n. 8, p. 696-703, 2016.

LONGUI, E. L. et al. Root-branch anatomical investigation of Eriotheca gracilipes young trees: a biomechanical and ecological approach. Scientia Forestalis, Piracicaba, v. 40, n. 93, p. 23-33, 2012.

MEIRELES, L. D.; KINOSHITA, L. S.; SHEPHERD, G. J. Composição florística da vegetação altimontana do distrito de Monte Verde (Camanducaia, MG), Serra da Mantiqueira Meridional, Sudeste do Brasil. Rodriguésia, Rio de janeiro, v. 65, n. 4, p. 831-859, 2014.

O'BRIEN, T. P.; FEDER, N.; MCCULLY, M. E. Polychromatic staining of plant cell walls by toluidine blue O. Protoplasma, New York, v. 59, n. 2, p. 368-373, jun. 1965.

PERDIZ, R. de O.; GIULIETTI, A. M.; OLIVEIRA, R. P. de. Flora da Bahia: Clethraceae. Sitientibus série Ciências Biológicas, Feira de Santana, v. 15, p. 1-4, 2015. DOI: 10.13102/scb342.

PEREIRA, J. A. et al. Crown architecture and leaf anatomic traits influencing herbivory on Clethra scabra Pers.: comparing adaptation to wetlands and drained habitats. Springer. Brazilian Journal of Botany, São Paulo, v. 40, n. 2, p. 481-490, 2017.

POMPEU, P. V. et al. Floristic composition and structure of an upper montane cloud forest in the Serra da Mantiqueira Mountain Range of Brazil. Acta Botanica Brasilica, Brasília, v. 28, n. 3, p. 456-464, 2014.

SÁ JÚNIOR, A. et al. Application of the Köppen classification for climatic zoning in the state of Minas Gerais, Brazil. Theoretical and Applied Climatology, Wien, v.108, p.1-7, 2012.

SOUZA, K. F. de. Comparação da anatomia foliar de Myrsine coriacea (Sw.) R. Br. ex Roem. \& Schult. e Myrsine umbellata Mart. em diferentes cotas altitudinais. 2014. Dissertação (Mestrado em Botânica Aplicada) - Universidade Federal de Lavras, Lavras, MG, 2014.

WANDERLEY, B. M. S. Atividade antiplasmódica e toxicológica de planta medicinais usadas no Brasil: uma abordagem etnobotânica. 2012. Dissertação (Mestrado em Ciências Biológicas) - Universidade Federal do Rio Grande do Norte, Natal, 2012. 


\section{Contribuição de Autoria}

\section{1 - Maria Luiza Santos}

Bióloga, Dra., Pesquisadora Autônoma

https://orcid.org/0000-0003-4233-8440•luiza_sauk@yahoo.com.br

Contribuição: Escrita - primeira redação, Escrita - revisão e edição; Validação

\section{2 - Alessandra de Oliveira Ribeiro}

Bióloga, Dra., Pesquisadora Autônoma

https://orcid.org/0000-0003-2075-2755 • alebioribeiro@gmail.com

Contribuição: Supervisão; Administração do projeto, Conceituação, Curadoria de dados

\section{3 - Evaristo Mauro de Castro}

Engenheiro Florestal, Dr., Professor

https://orcid.org/0000-0002-1385-8503 • evaristomcastro@gmail.com

Contribuição: Supervisão; Conceituação; Curadoria de dados

\section{4 - Kaline Fernandes Miranda}

Bióloga, Doutoranda em Botânica Aplicada

https://orcid.org/0000-0002-2898-4270•fkaline@gmail.com

Contribuição: Investigação, Metodologia

\section{5 - Marinês Ferreira Pires Lira}

Bióloga, Dra., Professora

https://orcid.org/0000-0003-0660-5775•marines.pires@ufla.br

Contribuição: Validação, Visualização de dados

\section{6 - Márcio Paulo Pereira}

Biólogo, Dr., Pesquisador

https://orcid.org/0000-0002-9245-7029•wartskt.bot@hotmail.com

Contribuição: Investigação; Visualização de dados, Obtenção de financiamento

\section{7 - Cassiana Alves Ferreira}

Bióloga, Dra., Pesquisadora

https://orcid.org/0000-0002-9559-6673•cassianaaf@gmail.com

Contribuição: Escrita - revisão e edição 


\section{8 - Fabio Akira Mori}

Engenheiro Florestal, Dr., Professor

https://orcid.org/0000-0002-7468-018X·mori@dcf.ufla.br

Contribuição: Supervisão; Validação; Curadoria de dados

\section{Como citar este artigo}

Santos, M. L.; Ribeiro, A. O.; Castro, E. M.; Miranda, K. F.; Lira, M. F. P.; Pereira, M. P.; Ferreira, C. A.; Mori, F. A. Anatomia comparada de Clethra scabra Pers. (Clethraceae) em diferentes altitudes na Serra da Mantiqueira, Minas Gerais, Brasil. Ciência Florestal, Santa Maria, v. 31, n. 3, p. 1407-1426, 2021. DOI 10.5902/1980509842333. Disponível em: https://doi. org/10.5902/1980509842333. Acesso em: xx mês-abreviado. 2021. 